\title{
Five-year outcomes of western mental health training for Traditional Chinese Medicine practitioners
}

\author{
Tai Pong Lam", Ki Yan Mak², Kwok Fai Lam³, Hoi Yan Chan and Kai Sing Sun ${ }^{1}$
}

\begin{abstract}
Background: There are increasing expectations for primary care practitioners to deal with mental health problems. In Hong Kong, $15 \%$ of the general public consult Traditional Chinese Medicine (TCM) practitioners regularly for their primary health care needs. This study investigated the 5-year outcomes of a western mental health training course for TCM practitioners in Hong Kong.

Method: Structured questionnaire surveys were conducted to compare the TCM practitioners' confidence and engagement in mental health care before and after the Course. The data collected during 2011-2015 were analyzed.

Results: A total of 151 TCM practitioners returned both pre- and post-Course questionnaires, with a response rate of $95.6 \%$. After the course, there were significant increases in the proportions of participants being confident of recognizing patients with psychological problems ( $62.9 \%$ before the course vs $89.4 \%$ after), diagnosing common mental health problems ( $47.7 \%$ vs $77.5 \%$ ), and managing them (31.2\% vs $64.3 \%)$. Overall, $66.9 \%$ of the participants reported some increase in their confidence in recognizing patients with psychological problems, diagnosing or/and managing patients with common mental health problems. Qualitative responses illustrated the major improvements were increased awareness of mental symptoms, better understanding of classification of mental disorders and management approaches. On the other hand, barriers included difficulties in understanding medical terms in English, consultation time constraints, and a lack of formal referral system to psychiatrists.
\end{abstract}

Conclusions: The Course has positive impact on TCM practitioners in handling mental health patients. The findings are useful for designing similar trainings on complementary and alternative medicine practitioners in other countries.

Keywords: Mental health, Postgraduate training, Psychiatrists, Traditional Chinese Medicine practitioners, Western medicine

\section{Background}

Since the last decade, the World Health Organization (WHO) has promoted the integration of mental health into primary care in response to the high prevalence of common mental disorders such as anxiety and depression $[1,2]$. Although there are rising expectations of primary care practitioners dealing with patients' mental health problems, many of them lack confidence in diagnosing and managing these cases $[3,4]$. To improve their competence, some postgraduate training courses

\footnotetext{
* Correspondence: tplam@hku.hk

'Department of Family Medicine and Primary Care, The University of Hong Kong, 3/F, Ap Lei Chau Clinic, 161 Main Street, Ap Lei Chau, Hong Kong Full list of author information is available at the end of the article
}

have been organized for western medicine primary care doctors and significant impacts were found in different countries [5-8]. The trained doctors recognized more mental health patients compared with those without training [9-11].

In Hong Kong, besides western medicine doctors, $15 \%$ of the general public consult Traditional Chinese Medicine (TCM) practitioners regularly for their primary health care needs $[12,13]$. TCM has been widely recognized as part of the health system in Hong Kong, with strong support from the post-colonial Government since 1997 such as the launch of licensing examination and full time undergraduate programmes in universities [14]. Notwithstanding the rise of stature, TCM practitioners 
inclined to gain better understanding of western medicine including treatment options and evidence-based practice $[14,15]$. Similar observations were shown among western studies, in which complementary and alternative medicine (CAM) practitioners addressed the need to acquire the skills of western conventional approach and guidelines $[16,17]$. Studies have demonstrated the benefits of overcoming the gap between TCM and western medicine towards treating organic disease [18]. By gaining better understanding in the diagnostic and management style from western medicine doctors, the TCM practitioners showed improved interrater reliability of diagnoses. Also, better communication and agreement might facilitate future referral and collaboration.

TCM does not differentiate between psychological and physiological functions, which are seen as interconnected [19]. TCM recognizes psychosomatic problems, similar to any other organic diseases, are resulted from the disequilibrium of yin-yang and the disorder of $q i$ and their viscera. The terms yin and yang represent two opposite yet interdependent properties of the body, whereas $q i$ is the vital energy that circulates along the meridian channels to supply to all major organs. Irregular emotional activity is believed to occur as a consequence of obtruded homeostasis between the polarities, or interfered flow of energy, in the organs [20]. There is no specific classification of mental disorders in TCM. [21, 22]. Instead, they are described as symptoms in a few general terms for example depressive mood, manic mood and madness. Our published paper reported the impact of an innovative 10-session western mental health training course for TCM practitioners [23]. To our knowledge, there had been no similar study in the literature. Adopting an inter-disciplinary and problemoriented approach, psychiatrists, clinical psychologists and family physicians were recruited to teach the training programme, in which 10 interactive seminars on topics related to common psychological problems and psychotherapy were offered (see Additional file 1). The Course aimed to increase TCM practitioners' capacity in recognition, diagnosis, basic management and referrals of mental health patients in primary care settings. Questionnaire survey on the first batch of TCM practitioners taking the Course in 2010 reported significant improvements in their confidence in recognizing patients with psychological problems $(60.6 \%$ being confident before the Course vs. $81.8 \%$ after), diagnosis (33 \% vs. $76 \%$ ) and management ( $24 \%$ vs. $55 \%$ ) of common mental health problems (e.g. anxiety, depression, sleeping disorder). Focus group interviews found that the training on western classification of mental illness was recognized as the most important reason for their improvement. We continued the pre- and post- course assessment survey subsequently for 5 years. This paper analyzed the data collected from the additional cohorts (2011-2015) which had five times the size of the previous sample (2010).
Apart from a stronger quantification of their improvement in mental health care, we are also able to explore the association between their learning outcomes and background characteristics. Further, the enablers and barriers they encountered can be summarized and analyzed. The findings should be useful to other countries where TCM practitioners and other CAM practitioners make significant contributions towards their health care services.

\section{Methods \\ Study design and data collection}

Structured questionnaires were designed for the immediate pre-course and post-course based on the review of relevant literature and comments from research team members. The questionnaires were pilot-tested in December 2009 and finalized in the following month. Same set of questions was used to compare the TCM practitioners' confidence and engagement in mental health care before and after attending the course. Open ended questions were included in the post-course survey to ask for qualitative responses about the impact of the course, barriers encountered and suggestions. The relevant questions for this study are shown in an additional file (see Additional file 2). Ethics approval was obtained from the Institutional Review Board of The University of Hong Kong/Hospital Authority Hong Kong West Cluster.

Over the five courses organized between 2011 and 2015, the students were invited to complete the pre-course survey at their first session and the immediate post-course survey after their final session. Verbal consent was obtained from the participating students when the questionnaires were handed out to them by the research assistants. In order to identify the respondent for comparisons between the anonymous pre-post- responses, each questionnaire was coded with a reference number which was known to one research assistant only and not available to other members of the research team.

\section{Data analysis}

Quantitative analysis was carried out using the statistical software SPSS version 23.0. The measurements were mainly shown in ordinal scale, statistical inference via the nonparametric Wilcoxon signed rank test was used to determine if there were significant changes in the median of the differences in the responses before and after taking the Course. A negative value in the median of the differences, hence a negative value of the test statistics, was an indication that the participants tended more on the agreed side or a higher number reported after taking the Course. We do not have hypotheses about the direction of the changes as a consequence of taking the Course as we do not wish to impose any subjective feelings that might bias the results. Two-sided tests were used throughout this study whenever appropriate. 
Furthermore, Fisher's exact test was used to test for the association between participants' background characteristics and reported learning outcomes. A $p$-value $<0.05$ was considered statistically significant.

The qualitative responses of open ended questions were analyzed with a thematic approach and grouped into common themes independently by two investigators who were both experienced in qualitative research. The consistency between the two entries was checked.

\section{Results}

\section{Survey participants}

The pre-course questionnaire survey had a $100 \%$ response rate, with 158 questionnaires completed, whereas the postcourse survey attained a $95.6 \%$ response rate with a total of 151 returned valid questionnaires. Responses from the 151 participants who completed both rounds of questionnaires were used in the analysis to compare if there were significant differences between the pre- and post-survey of individual participants. Among the participants, $42.4 \%$ were male and $57.6 \%$ were female, all working in the public health care sector. The mean (SD) years after graduation from TCM training was 2.5 (1.71).

\section{Effect on confidence and engagement in mental health care}

The pre- and post-course survey responses are compared in Table 1. There were significant increases in the proportions of participants being confident of recognizing patients with psychological problems (62.9 \% before vs $89.4 \%$ after), diagnosing common mental health problems $(47.7 \%$ vs $77.5 \%$ ), and managing them ( $31.2 \%$ vs $64.3 \%$ ). There was also a $7.2 \%$ increase in the proportion of participants reporting positive experiences regarding patients with mental disorders.

Qualitative responses to the open-ended questions illustrated the causes of improvement, which included higher awareness of psychosomatic symptoms, better understanding of classification of mental disorders, and management approaches shared by western medicine primary care doctors and psychiatrists.

\section{Some small things could indicate a mental problem} which I never knew before.

The contents of the course facilitate me in differentiating whether a patient suffers from mental health problem and how to manage it. I'm particularly inspired by the talks on OCD, bipolar disorder and schizophrenia.

The cases shared by the doctors. Most doctors share their experiences and skills in tackling the problems.
Apart from applying the western medicine approach, some TCM practitioners realized their potential roles in providing care to mental health patients.

\section{Extraordinary; open-minded, and not having the western dominant attitude.}

Diagnosis of mental health problems and the side effects which occur after taking [western medicine] pills. I realize we can give herbs or acupuncture to decrease [side effects] and make patients feel better.

On the other hand, difficulties in understanding medical terms in English and indications of western medications were reported by some participants.

Too many English terms of western medication and diagnosis which are not well understood.

The knowledge gap in western medications makes it difficult to actually understand what the drugs are for.

The proportion of participants being confident of referring a patient with mental health problem to other health care professionals increased ( $52.3 \%$ vs $80.7 \%$ ). However, there was no significant change in percentage of mental health patients being recommended by the participants to western medicine doctors due to the lack of a formal referral system in Hong Kong. Besides, no significant change was indicated in terms of time sufficiency in handling patients with mental health problems. These barriers are explained in the qualitative responses.

There is no system for TCM practitioners to formally refer patients to western medicine doctors.

No clue on what should be done if the patient can't be helped

\section{Insufficient time to take a full history of patients with mental health problems}

Clinical work is too busy for me to understand the background of each patient

Besides, negative attitude of some patients, which could be due to their mental illness, might discourage the TCM practitioners from caring their mental health problems.

The negative/rude attitude of the patient is so discouraging that the doctor would lose their patience to communicate with the patient 
Table 1 Changes in confidence and engagement in the care of patients with mental health problems

\begin{tabular}{|c|c|c|c|c|c|}
\hline & \multicolumn{2}{|c|}{ Pre-course $(n=151)$} & \multicolumn{2}{|c|}{ Post-course $(n=151)$} & \multirow[t]{2}{*}{ Wilcoxon signed rank t } \\
\hline & $\mathrm{N}$ & $(\%)$ & $\mathrm{N}$ & (\%) & \\
\hline \multicolumn{6}{|c|}{ I am confident of recognizing patients with psychological problems } \\
\hline Strongly disagree & 1 & $(0.7)$ & 2 & $(1.3)$ & $Z=-5.410, p<0.001^{* *}$ \\
\hline Disagree & 55 & $(36.4)$ & 14 & (9.3) & \\
\hline Agree & 93 & $(61.6)$ & 128 & $(84.8)$ & \\
\hline Strongly agree & 2 & (1.3) & 7 & (4.6) & \\
\hline
\end{tabular}

I am confident of diagnosing patients with common mental health problems (e.g. anxiety, depression, sleeping disorder)

$\begin{array}{llllll}\text { Strongly disagree } & 6 & (4.0) & 1 & (0.7) & Z \\ \text { Disagree } & 73 & (48.3) & 33 & (21.9) & \\ \text { Agree } & 69 & (45.7) & 112 & (74.2) \\ \text { Strongly agree } & 3 & (2.0) & 5 & \text { (3.3) }\end{array}$

I am confident of managing patients with common mental health problems

$\begin{array}{llllll}\text { Strongly disagree } & 9 & (6.0) & 2 & (1.3) & \mathrm{Z}=-5.895, p<0.001^{* *} \\ \text { Disagree } & 95 & (62.9) & 52 & (34.4) \\ \text { Agree } & 46 & (30.5) & 96 & (63.6) \\ \text { Strongly agree } & 1 & (0.7) & 1 & (0.7)\end{array}$

I have enough time in my practice to handle patients with mental health problems

$\begin{array}{llllll}\text { Strongly disagree } & 14 & (9.3) & 12 & (7.9) & Z \\ \text { Disagree } & 89 & (58.9) & 86 & (57.0) & \\ \text { Agree } & 47 & (31.1) & 51 & \text { (33.8) } \\ \text { Strongly agree } & 1 & (0.7) & 2 & \text { (1.3) }\end{array}$

My experiences regarding patients with mental health problems

$\begin{array}{llllll}\text { Generally positive } & 28 & (18.8) & 39 & (26.0) & Z=-2.287, p=0.022^{*} \\ \text { Neutral } & 109 & (73.2) & 106 & (70.7) \\ \text { Generally negative } & 12 & (8.1) & 5 & \text { (3.3) }\end{array}$

I am confident of referring a patient with mental health problem to other health care professionals if necessary

$\begin{array}{llllll}\text { Strongly disagree } & 7 & (4.6) & 1 & (0.7) & Z=-5.918, p<0.001^{* *} \\ \text { Disagree } & 65 & (43.0) & 28 & (18.7) & (70.0) \\ \text { Agree } & 74 & (49.0) & 105 & (10.7)\end{array}$

Percentage of patients with mental health problems being recommended by me to western medicine doctors

\begin{tabular}{llllll}
$0 \%$ & 88 & $(71.5)$ & 86 & $(74.1)$ & $Z=-0.244, p=0.807$ \\
$1-10 \%$ & 21 & $(17.1)$ & 18 & $(15.5)$ & \\
$11-20 \%$ & 5 & $(4.1)$ & 6 & $(5.2)$ \\
$21-30 \%$ & 2 & $(1.6)$ & 2 & $(1.7)$ \\
$>30 \%$ & 7 & $(5.7)$ & 4 & $(3.5)$ \\
\hline
\end{tabular}

Suggestions were made by the participants to further enhance the learning outcomes of the course. They included delivering a more comprehensive session on cognitivebehavioral therapy and counselling, having more pragmatic approach with emphasis on integrating TCM with western medicine in helping patients with mental disorders, and involving TCM practitioners who are experienced in handling mental health problems as tutors.
Relationship between participants' background characteristics and reported learning outcomes

Participants were classified into two groups according to their reported learning outcomes (Table 2). A total of $66.9 \%$ of participants marked some increase in confidence in recognizing patients with psychological problems, diagnosis or/and management of patients with common mental health problems. Participants who had received 
Table 2 Association between respondents' background characteristics and reported learning outcomes

\begin{tabular}{|c|c|c|c|c|c|}
\hline & \multicolumn{4}{|c|}{$\begin{array}{l}\text { Increased confidence in recognition, diagnosis or/and } \\
\text { management }\end{array}$} & \multirow{3}{*}{$\begin{array}{l}\text { Fisher's exact test } \\
\text { (Yes vs No) } \\
p \text {-value }\end{array}$} \\
\hline & \multicolumn{2}{|c|}{ Yes $(n=101)$} & \multicolumn{2}{|c|}{ No $(n=50)$} & \\
\hline & $\bar{N}$ & $(\%)$ & $\bar{N}$ & $(\%)$ & \\
\hline \multicolumn{6}{|l|}{ Personal background } \\
\hline Gender & & & & & 0.2955 \\
\hline Male & 40 & 39.6 & 24 & 49.0 & \\
\hline Female & 61 & 60.4 & 25 & 51.0 & \\
\hline Undergraduate TCM training & & & & & $0.0085^{*}$ \\
\hline Hong Kong & 93 & 92.1 & 36 & 75.0 & \\
\hline Mainland China & 8 & 7.9 & 12 & 25.0 & \\
\hline Having postgraduate qualification & & & & & $0.0120^{*}$ \\
\hline Yes & 26 & 27.4 & 21 & 50.0 & \\
\hline No & 69 & 72.6 & 21 & 50.0 & \\
\hline \multicolumn{6}{|l|}{ Reasons for studying this Course } \\
\hline Meet job demand & & & & & 0.3753 \\
\hline Least important & 3 & $3.0 \%$ & 2 & $4.0 \%$ & \\
\hline Unimportant & 33 & $32.7 \%$ & 10 & $20.0 \%$ & \\
\hline Important & 55 & $54.5 \%$ & 31 & $62.0 \%$ & \\
\hline Very important & 10 & $9.9 \%$ & 7 & $14.0 \%$ & \\
\hline Interest in community psychological medicine & & & & & 0.4207 \\
\hline Least important & 1 & $1.0 \%$ & 1 & $2.0 \%$ & \\
\hline Unimportant & 1 & $1.0 \%$ & 2 & $4.0 \%$ & \\
\hline Important & 52 & $51.5 \%$ & 27 & $54.0 \%$ & \\
\hline Very important & 47 & $46.5 \%$ & 20 & $40.0 \%$ & \\
\hline Interest in western medicine & & & & & 0.6594 \\
\hline Least important & 1 & $1.0 \%$ & 1 & $2.0 \%$ & \\
\hline Unimportant & 19 & $19.0 \%$ & 8 & $16.0 \%$ & \\
\hline Important & 57 & $57.0 \%$ & 26 & $52.0 \%$ & \\
\hline Very important & 23 & $23.0 \%$ & 15 & $30.0 \%$ & \\
\hline \multicolumn{6}{|l|}{ Attitudes towards western medicine } \\
\hline I am comfortable to be taught by western medicine doctors & & & & & $0.0215^{*}$ \\
\hline Strongly disagree & 1 & $1.0 \%$ & 0 & $0.0 \%$ & \\
\hline Disagree & 3 & $3.0 \%$ & 8 & $16.0 \%$ & \\
\hline Agree & 66 & $65.3 \%$ & 31 & $62.0 \%$ & \\
\hline Strongly agree & 31 & $30.7 \%$ & 11 & $22.0 \%$ & \\
\hline $\begin{array}{l}\text { Postgraduate courses taught by western medicine doctors } \\
\text { can help me look after my patients with common mental } \\
\text { health problems }\end{array}$ & & & & & 0.1029 \\
\hline Strongly disagree & 3 & $3.0 \%$ & 1 & $2.0 \%$ & \\
\hline Disagree & 2 & $2.0 \%$ & 4 & $8.0 \%$ & \\
\hline Agree & 76 & $76.0 \%$ & 41 & $82.0 \%$ & \\
\hline Strongly agree & 19 & $19.0 \%$ & 4 & $8.0 \%$ & \\
\hline $\begin{array}{l}\text { I am confident of integrating western medicine approach } \\
\text { in my daily clinical practice of TCM }\end{array}$ & & & & & 0.9222 \\
\hline Strongly disagree & 2 & $2.0 \%$ & 1 & $2.0 \%$ & \\
\hline
\end{tabular}


Table 2 Association between respondents' background characteristics and reported learning outcomes (Continued)

\begin{tabular}{|c|c|c|c|c|c|}
\hline Disagree & 18 & $17.8 \%$ & 7 & $14.0 \%$ & \\
\hline Agree & 69 & $68.3 \%$ & 35 & $70.0 \%$ & \\
\hline Strongly agree & 12 & $11.9 \%$ & 7 & $14.0 \%$ & \\
\hline \multicolumn{6}{|l|}{ Views on providing mental health care } \\
\hline $\begin{array}{l}\text { I have enough time in my practice to handle patients } \\
\text { with mental health problems }\end{array}$ & & & & & 0.4458 \\
\hline Strongly disagree & 11 & $10.9 \%$ & 3 & $6.0 \%$ & \\
\hline Disagree & 58 & $57.4 \%$ & 31 & $62.0 \%$ & \\
\hline Agree & 32 & $31.7 \%$ & 15 & $30.0 \%$ & \\
\hline Strongly agree & 0 & $0.0 \%$ & 1 & $2.0 \%$ & \\
\hline $\begin{array}{l}\text { My experiences regarding patients with mental health } \\
\text { problems are }\end{array}$ & & & & & 0.5142 \\
\hline Positive & 16 & $16.2 \%$ & 12 & $24.0 \%$ & \\
\hline Neutral & 74 & $74.7 \%$ & 35 & $70.0 \%$ & \\
\hline Negative & 9 & $9.1 \%$ & 3 & $6.0 \%$ & \\
\hline
\end{tabular}
${ }^{*} p<0.05$

their undergraduate TCM training in Hong Kong ( $p=$ $0.0085)$, with no previous postgraduate qualification $(p=0.0120)$, or felt comfortable to be taught by western medicine doctors $(p=0.0215)$ were significantly more likely to show improvement.

\section{Discussion}

This study on a 5 -year sample showed that $66.9 \%$ of the participants perceived their mental health care management had improved after attending the 10-session training course. The results reinforced the positive outcomes shown by our previous study [23]. Besides, the influencing background characteristics, enablers and barriers of improvement were identified.

Behavioral studies had illustrated the positive association between learning outcomes and flexibility in learning [24]. Mills et al. [25] pointed out the importance of intellectual openness for TCM practitioners to overcome the discrepancies in the practice of TCM and western medicine. In our study, participants who were more comfortable learning from western medicine doctors perceived greater gains from the programme. The medium of instruction, which was a mixture of Cantonese and English, could have an impact as well. It could be more suitable for practitioners who graduated from local institutions in Hong Kong. Previous research found that whether the teaching delivered was tailor-made to the practitioners was crucial for the learning outcomes [26]. It was therefore more likely for our students to have enhanced confidence and better integration into their clinical practices when a mixture of Cantonese and English was used for the teaching.

The reasons of improvement were described in the qualitative responses. The open-minded attitudes of the teachers and case sharing encouraged the TCM practitioners to learn and apply western medicine approach. Some TCM practitioners also realized the possibility in enhancing care to the mental health patients by TCM approach. On the other hand, barriers were mentioned by some participants. Apart from learning factors such as difficulties in understanding medical terms in English and the knowledge gap between Chinese and Western medicine, some encountered problems of consultation time constraints and patients' negative attitude. In fact, these are typical barriers encountered by western medicine primary care doctors too [27]. However, significant improvement in time efficiency $(55.8 \%$ before the course vs $72.1 \%$ after) had been reported in our study on mental health course for western medicine doctors [5]. In the future, the teachers of the course should address these practical barriers and share their personal experience with the TCM practitioners to explore possible solutions. Some participants preferred to have a more comprehensive session on cognitive-behavioral therapy and counseling. While this might be of benefits to some students, such a session would be beyond the learning objectives of this 10-session training course which aimed to provide a basic training in handling mental health patients. The most fundamental objective was to enable TCM practitioners to recognize psychological problems and psychosomatic symptoms, and not to mistreat them as purely physical illnesses. We, however, expected some students would be motivated to pursue further training in specific areas. This study also found that the students' increased intention in referring mental health patients did not lead to a significant increase in referral rate. The atmosphere in the real clinical setting was less optimal than that of the classroom where the teachers generally supported integration of TCM and western medicine. The 
lack of a formal referral system, as well as the western medicine doctors' concerns about applying TCM when the patients are taking western medications [28], would discourage the collaboration. As suggested by some students, the course can involve TCM practitioners as tutors. This may help to provide the students and course organizers the strategies to overcome the barriers of collaboration.

This study has several limitations. First, due to the lack of a control group, the specific effects of the training course could not be quantified fully. Second, the findings were based on self-reported data from the TCM practitioners. Other measurements like patient questionnaires, diagnostic screening tools [29], and skill assessment using standardized role-played scenarios [7] would be helpful to further confirm the results of this study. Third, despite the larger sample size, our sampled group was the new and major upcoming generation of TCM practitioners in Hong Kong from the public health care setting.

\section{Conclusion}

The Course has positive impact on TCM practitioners in handling mental health patients. The main areas of improvement included increased awareness of mental symptoms, better understanding of classification of mental disorders and management approaches. On the other hand, barriers included difficulties in understanding medical terms in English, consultation time constraints, and a lack of formal referral system to psychiatrists. The findings are useful for designing similar trainings on CAM practitioners in other countries.

\section{Additional files}

Additional file 1: The course curriculum. (DOCX $14 \mathrm{~kb}$ )

Additional file 2: Questions of pre-course and post course surveys. (DOC $143 \mathrm{~kb}$ )

\section{Abbreviations}

CAM: Complementary and alternative medicine; TCM: Traditional Chinese Medicine

\section{Acknowledgements}

The authors would like to thank participants of the Postgraduate Community Psychological Medicine Programme for Traditional Chinese Medicine practitioners for completing the questionnaire.

\section{Funding}

None.

\section{Availability of data and materials}

All relevant data are within the manuscript.

\section{Authors' contributions}

TP Lam, KY Mak and KS Sun wrote the protocol. KY Mak, KS Sun and HY Chan coordinated the study. KF Lam, HY Chan and KS Sun undertook the statistical analysis. TP Lam, HY Chan and KS Sun wrote the first draft. All authors participated in the drafting and approval of the final version of the manuscript.

\section{Competing interests}

The authors declare that they have no competing interests.
Consent for publication

Not applicable.

\section{Ethics approval and consent to participate}

Ethics approval was obtained from the Institutional Review Board of The University of Hong Kong/Hospital Authority Hong Kong West Cluster. Verbal consent was obtained from the participating students when the questionnaires were handed out to them by the research assistants.

\section{Author details}

${ }^{1}$ Department of Family Medicine and Primary Care, The University of Hong Kong, 3/F, Ap Lei Chau Clinic, 161 Main Street, Ap Lei Chau, Hong Kong.

${ }^{2}$ Mental Health Association of Hong Kong, Kwun Tong, Hong Kong.

${ }^{3}$ Department of Statistics and Actuarial Science, The University of Hong

Kong, Pok Fu Lam, Hong Kong.

Received: 12 July 2016 Accepted: 20 October 2016

Published online: 26 October 2016

\section{References}

1. World Health Organization. Integrating mental health into primary care: a global perspective. Geneva: World Health Organization; 2008.

2. Demyttenaere $K$, Bruffaerts R, Posada-Villa J, Gasquet I, Kovess V, Lepine JP, Angermeyer MC, Bernert S, de Girolamo G, Morosini P, et al. Prevalence, severity, and unmet need for treatment of mental disorders in the World Health Organization World Mental Health Surveys. JAMA. 2004;291(21):2581-90.

3. Jackson JL, Passamonti M, Kroenke K. Outcome and impact of mental disorders in primary care at 5 years. Psychosom Med. 2007;69(3):270-6.

4. Hickie IB, Davenport TA, Scott EM, Hadzi-Pavlovic D, Naismith SL, Koschera A. Unmet need for recognition of common mental disorders in Australian general practice. Med J Aust. 2001;175(Suppl):S18-24.

5. Lam TP, Goldberg D, Tse EY, Lam KF, Mak KY, Lam EW. What do primary care doctors get out of a year-long postgraduate course in community psychological medicine? Int J Psychiatry Med. 2011;42(2):133-49.

6. Naismith SL, Hickie IB, Scott EM, Davenport TA. Effects of mental health training and clinical audit on general practitioners' management of common mental disorders. Med J Aust. 2001;175(Suppl):S42-47.

7. Walters P, Tylee A, Fisher J, Goldberg D. Teaching junior doctors to manage patients who somatise: is it possible in an afternoon? Med Educ. 2007; 41(10):995-1001.

8. Zakroyeva A, Goldberg D, Gask L, Leese M. Training Russian family physicians in mental health skills. Eur J Gen Pract. 2008;14(1):19-22.

9. Copty M, Whitford DL. Mental health in general practice: assessment of current state and future needs. Ir J Psychol Med. 2005:22(03):83-6.

10. Lam TP, Lam KF, Lam EW, Sun KS. Does postgraduate training in community mental health make a difference to primary care Physicians' attitudes to depression and schizophrenia? Community Ment Health J. 2015; 51(6):641-6.

11. Richards JC, Ryan P, McCabe MP, Groom G, Hickie IB. Barriers to the effective management of depression in general practice. Aust N Z J Psychiatry. 2004; 38(10):795-803.

12. Chung V, Lau CH, Yeoh EK, Griffiths SM. Age, chronic non-communicable disease and choice of traditional Chinese and western medicine outpatient services in a Chinese population. BMC Health Serv Res. 2009;9:207.

13. Census and Statistics Department, Hong Kong SAR Government. Thematic household survey report no. 45. 2010.

14. Chung VC, Law MP, Wong SY, Mercer SW, Griffiths SM. Postgraduate education for Chinese medicine practitioners: a Hong Kong perspective. BMC Med Educ. 2009:9:10.

15. Hadley J, Hassan I, Khan KS. Knowledge and beliefs concerning evidence-based practice amongst complementary and alternative medicine health care practitioners and allied health care professionals: a questionnaire survey. BMC Complement Altern Med. 2008;8:45

16. Frenkel M, Ben-Arye $\mathrm{E}, \mathrm{Geva} \mathrm{H}$, Klein A. Educating CAM practitioners about integrative medicine: an approach to overcoming the communication gap with conventional health care practitioners. J Altern Complement Med. 2007;13(3):387-91.

17. Leach MJ, Gillham D. Are complementary medicine practitioners implementing evidence based practice? Complement Ther Med. 2011;19(3):128-36. 
18. Mist S, Ritenbaugh C, Aickin M. Effects of questionnaire-based diagnosis and training on inter-rater reliability among practitioners of traditional Chinese medicine. J Altern Complement Med. 2009;15(7):703-9.

19. Leung JP. Emotions and mental health in Chinese people. J Child Fam Stud. 1998;7(2):115-28.

20. Yang W, Meng F, Jiang Y. Diagnostics of traditional Chinese medicine. Beijing: Academy Press; 1998.

21. Cai J. Advanced textbook on traditional Chinese medicine and pharmacology, vol. 1. Beijing: New World Press; 1995.

22. Aung SK, Fay H, Hobbs 3rd RF. Traditional Chinese medicine as a basis for treating psychiatric disorders: a review of theory with illustrative cases. Med Acupunct. 2013;25(6):398-406.

23. Lam TP, Mak KY, Goldberg D, Lam KF, Sun KS. Western mental health training for traditional Chinese medicine practitioners. Acta Psychiatr Scand. 2012;126(6):440-7.

24. Chowdhury MS, Amin MN. Personality and students' academic achievement: interactive effects of conscientiousness and agreeableness on students' performance in principles of economics. Soc Behav Pers. 2006;34(4):381-8.

25. Mills E, Hollyer T, Saranchuk R, Wilson K. Teaching Evidence-Based Complementary and Alternative Medicine (EBCAM); changing behaviours in the face of reticence: a cross-over trial. BMC Med Educ. 2002;2:2.

26. Hadley JA, Davis J, Khan KS. Teaching and learning evidence-based medicine in complementary, allied, and alternative health care: an integrated tailor-made course. J Altern Complement Med. 2007;13(10):1151-5.

27. Sun KS, Lam TP, Lam KF, Lo TL. Obstacles in managing mental health problems for primary care physicians in Hong Kong. Adm Policy Ment Health. 2015:42(6):714-22.

28. Lam TP, Sun KS. Dilemma of integration with Western medicine - views of Traditional Chinese Medicine practitioners in a predominant Western medical setting. Complement Ther Med. 2013;21(4):300-5.

29. Carey M, Jones K, Meadows G, Sanson-Fisher R, D'Este C, Inder K, Yoong SL, Russell G. Accuracy of general practitioner unassisted detection of depression. Aust N Z J Psychiatry. 2014;48(6):571-8.

\section{Submit your next manuscript to BioMed Central and we will help you at every step:}

- We accept pre-submission inquiries

- Our selector tool helps you to find the most relevant journal

- We provide round the clock customer support

- Convenient online submission

- Thorough peer review

- Inclusion in PubMed and all major indexing services

- Maximum visibility for your research

Submit your manuscript at www.biomedcentral.com/submit

Biomed Central 